\title{
Biochemical assessment of oxidative stress by the use of açai (Euterpe oleracea Martius) gel in physically active individuals
}

\author{
Daniela Soares VIANA ${ }^{1}$, Lucia Maria Jaeger de CARVALHO ${ }^{1 \star}$, Mirian Ribeiro Leite MOURA², \\ Jacqueline Carvalho PEIXOTO², José Luiz Viana de CARVALHO ${ }^{3}$
}

\begin{abstract}
The relation between oxidative stress and inflammation induced by diseases and exercise has increased the interest in the benefits of antioxidant supplements in the improvement of health and physical and mental performance. The aim of this study was to evaluate the effectiveness of açai gel in reducing oxidative stress in individuals engaged in physical activities as well as their acceptance. Sensory evaluation was performed to determine its acceptability and the biochemical parameters related to immune profile and biomarkers of muscle, liver and oxidative stress, with and without the use of gel were evaluated. The appearance, sweetness and overall impression of the açai gel were considered good. It was observed a significant increase in CK enzyme, without the gel as well as the oxidative stress biomarkers, it was observed that the MDA (with and without gel) a significant increase $(\mathrm{p}<0.05)$. Through biochemical evaluation, it is concluded that the gel provided protection for some of parameters studied, since it modulated the immunological parameter reducing the lymphocyte activity and muscular stress. However, more studies must be carried out with a larger number of individuals to confirm the gel functionality.
\end{abstract}

Keywords: açai; sensory analysis; biochemical evaluation.

Practical Application: Enhance performance of physically active individuals.

\section{Introduction}

In Brazil are found five species of the genus Euterpe: E. edulis Martius, E. catinga Wallace, E. oleracea Martius, E. longebracteata and E. precatoria Martius. From these, only the first spread until southern Brazil through the Atlantic coast. The other species are distributed in the Amazon rainforest (Henderson, 2000).

Açaí is a very important food in the diet of northern Brazil, where its consumption dates back to pre-Columbian times being considered an exotic delicacy and appreciated in various regions of Brazil and the world. The states of Amazonas and Pará in Brazil are the largest producers of this fruit, together they are responsible for over $85 \%$ of world production (Malcher \& Amaral, 2009; Hogan et al., 2010).

Wide availability of elaborate drinks with tropical fruits and enriched with antioxidant nutrients is reaching great popular interest by the desire of consumers to incorporate more healthy foods to their regular diet, while the industries have focused on the production of beverages claiming healthiness as a market differential (Muñoz et al., 2010).

Açaí is a viable option to enrich different formulations, given its composition rich in flavonoids (high anthocyanin content) as well as being fruit, widely grown in Brazil and commercialized in the form of frozen pulp (Hogan et al., 2010). The beneficial effects attributed to açai and its derivatives are associated with its significant content in phenolic compounds, which stimulated various researchers to identify such compounds and evidencing their pharmacological properties, including anti-proliferative, anti-inflammatory, antioxidant and cardioprotective activities (Heinrich et al., 2011).

According to Pietta (2000), the excess of free radicals in the body can be combated with antioxidants produced in the body or absorbed from the diet ( $\alpha$-tocopherol, $\beta$-carotene, ascorbic acid and phenolic compounds such as flavonoids and poly flavonoids), which, when present at low concentrations compared to the oxidizable substrate, regenerate or prevent significantly its oxidation.

Evidence suggests that some of these benefits attributed to regular physical activity are related to a reduction of the levels of inflammatory markers and oxidative stress, especially if associated with good eating habits (Laufs et al., 2005; Peake et al., 2007).

The relation between oxidative stress and inflammation-induced by diseases and exercise has increased the interest in the benefits of antioxidant supplements the seek improvement of health and physical and mental performance (Valko et al., 2006; McAnulty et al., 2011, 2013). The aim of this study is to evaluate the effectiveness of açai gel in reducing oxidative stress in individuals engaged in physical activity, as well as its acceptance.

${ }^{1}$ Laboratório de Tecnologia e Análise Instrumental de Alimentos, Departamento de Produtos Naturais e Alimentos, Faculdade de Farmácia, Universidade Federal do Rio de Janeiro - UFRJ, Rio de Janeiro, RJ, Brasil

${ }^{2}$ Laboratório de Composição Química e Bromatologia dos Alimentos, Departamento de Produtos Naturais e Alimentos, Faculdade de Farmácia, Universidade Federal do Rio de Janeiro - UFRJ, Rio de Janeiro, RJ, Brasil

${ }^{3}$ Departamento de Cereais, Centro de Tecnologia e Análise de Alimentos, Embrapa Agroindústria de Alimentos - EMBRAPA, Rio de Janeiro, RJ, Brasil

*Corresponding author: luciajaeger@gmail.com 


\section{Materials and methods}

\subsection{Açai gel formulation}

The gel was obtained by Carvalho et al. (2015).

\subsection{Determination of proximate and nutritional composition of açaí gel}

The moisture, ash, total nitrogen, total solids, total lipid and proteins content were determined according to AOAC (Association of Official Analytical Chemists, 2005). Quantification of total carbohydrates (NIFEXT), including fibers, was calculated by the difference between 100 and the sum of moisture, ash, total lipids and proteins (Association of Official Analytical Chemists, 2005).

The mineral concentration was determined by mass spectrometry with plasma inductively coupled in the mode without quantitative, using equipment ELAN 6000 Perkin Elmer-Sciex. Fatty acids were determined by Hartman \& Lago (1973).

\subsection{Sensory evaluation of açaí gel}

Was performed in order to determine the acceptability (Caleguer \& Benassi, 2007) of açai gel by not trained ordinary consumers, and it was performed in two stages: the first among physically active individuals in two gyms located in the neighborhood of Tijuca $(\mathrm{n}=40)$ who conducted the clinical trial; the second among the participants of the Fair FAPERJ of Science, Technology and Innovation $(\mathrm{n}=128)$. It was used hedonic scale of nine points for the attributes color, flavor, appearance and texture.

Samples were served to the tasters in disposable cups with $30 \mathrm{ml}$ capacity. The general acceptance and by color, flavor, appearance and texture attributes was evaluated, using hedonic scale of 9 points, being considered: 9 - liked extremely 1 - extremely disliked. The purchase intention was evaluated using scale ranging from 1 to 5 , where 5 certainly buy 1 - certainly would not buy. The results were treated by analysis of variance (Statistica 6.0).

Given the ethical aspects, all volunteers who agreed to participate in this study signed on a voluntary basis, an informed consent form. With approval from the Ethics Committee in Research of the State University of Rio de Janeiro (019/2012).

\subsection{Nutritional assessment and dietary habits}

The assessment of habitual dietary intake was conducted prior to the trial, in order to analyze and evaluate the nutritional status of individuals before the test, and verification of the adequacy of nutrients in the usual diet for the inclusion of the individuals after the clinical trial and the implementation of physical tests without risk of compromising the volunteers' performance. The evaluation of the most common eating habits was conducted through a diet recall (Gouveia, 1978). The nutritional value and consumption of antioxidants from the diet of the participants was analyzed by Virtual Nutriplus ${ }^{\circledR}$ software, 2008, SP, Brazil.

The average consumption of macro and micronutrients were estimated through software and compared to the dietary reference intake, have been assessed.

\subsection{Clinical trial and biochemical analysis}

The sample for the in vivo tests consisted of 24 male volunteers, experienced in strength training, with age ranging between 21-42 years with at least six months of continuous training and minimum attendance of four times a week. For the selection of volunteers were considered the following exclusion criteria: not to use drugs, anabolic steroids or nutritional supplements during the survey period and not being carriers of infectious and inflammatory diseases.

The collection of clinical trial data was divided into two stages. In the first stage, were carried out tests of maximum repetition and collected data for anthropometric measurements and nutrition of individuals to be selected for the study. The second step of the clinical trial was the implementation of strength training in two days, the first with no intake of the functional energy gel and the second day after an acute supplementation with the gel.

The participants were instructed to consume two sachets of gel containing $45 \mathrm{~g}$ each for three consecutive days, and one sachet before performing the second day of strength training. During this step, the volunteers were instructed to maintain a balanced diet and avoid eating foods with antioxidant properties.

For biochemical analyzes, the subjects underwent blood sampling before (time 1) and after physical effort (time 2) without (first day at the times 1 and 2) and, with the intake of functional energy gel (second day in times 1 and 2) to analyze the hematological profile and markers of muscle and oxidative stress.

Blood collection was performed through heparin catheter in forearm vein of each individual by vacuum system $\left(\right.$ Vacuntainer $\left.^{\circledR}\right)$. The collected blood was separated into test tubes for each pre-defined biochemical parameter.

Were evaluated biochemical parameters related to immunological profile and biomarkers of muscle, liver and oxidative stress. The biochemical analysis of markers of immunological, muscle, liver and oxidative stress conducted in the study were of paramount Importance for the detection of yield drop by muscle acidosis and, therefore, risk for reduced strength. In addition, this assessment is needed to better understand the metabolism of trained bodybuilders when subjected to strength testing at $80 \%$ of $1 \mathrm{MR}$.

\subsection{Statistical analysis}

The statistical analysis was performed using analysis of variance (ANOVA) at a significance level of $P<0.05$. Duncan's test was used to determine the differences between the means. The analyses were performed with Microsoft Excel.

\section{Results and discussion}

\subsection{Proximate and nutritional composition of açaí gel}

The values of the chemical composition of the gel, regarding to moisture, ash, protein, lipids and total carbohydrates were 60.48; $3.89 ; 2: 01 ; 5.82$ and $27.80(\mathrm{~g} / 100 \mathrm{~g})$, respectively. The moisture content after the preparation of the gel, reduced by $28.93 \%$, which is expected with the gelling process; while lipid levels decreased by $36.04 \%$. 
Vitamins A and E ( $\alpha$-tocopherol) potential antioxidants were found in the açai gel in average concentrations of $6.84 \mathrm{IU} / \mathrm{g}$ and $33.08 \mathrm{mg} / \mathrm{kg}$, respectively. The oxidative stability was greater than 1232 days (about 40 months and 3.3 years).

Spada et al. (2009) analyzed the mineral content of 23 samples of frozen fruit by PIXE method (Particle Induced X ray). All fruits, including açai pulp, presented $\mathrm{Fe}, \mathrm{Mg}, \mathrm{Cl}, \mathrm{P}, \mathrm{K}$ and $\mathrm{Na}$. The açai showed significant levels of $\mathrm{Fe}$, being observed by the authors that $100 \mathrm{~g}$ of this fruit can contribute with approximately $7 \%$ of the Recommended Daily Intake (RDI) for men; whereas $\mathrm{Zn}$ levels found in frozen pulps are capable of supplying about $2 \%$ of RDI for men and 3\% for women.

Concerning to the content of oleic fatty acid, the value found in this study $(28.69 \mathrm{~g} / 100 \mathrm{~g})$ was much lower than those reported by Nascimento et al. (2008), Schauss et al. (2006) and Rogez (2000) in açai fruit (E. oleracea) $(52.00 \mathrm{~g} / 100 \mathrm{~g}, 36.20 \mathrm{~g} / 100 \mathrm{~g}$ and $54.9 \mathrm{~g} / 100 \mathrm{~g}$, respectively). The fatty linoleic acid showed lower concentration $(6.24 \mathrm{~g} / 100 \mathrm{~g})$ when compared to values found by Schauss et al. (2006) (12.50 g/100 g) and Nascimento et al. (2008) $(11.28 \mathrm{~g} / 100 \mathrm{~g})$.

The levels of carbohydrates, crude fiber and minerals (zinc and iron) present in the gel to be used in the clinical trial with athletes (Table 1). The total soluble solids content was of $39.52 \mathrm{~g} / 100 \mathrm{~g}$.

The content of fatty acids present in the açai gel are shown in Table 2.

According to the results obtained, the gel has a good content of nutrients and amino acid profile (essential and non-essential), with no significant differences between the amino acids arginine and leucine $(0.09 \mathrm{~g} / 100 \mathrm{~g})$; valine and serine $(0.07 \mathrm{~g} / 100 \mathrm{~g})$; alanine, lysine, phenylalanine, threonine, and proline $(0.06 \mathrm{~g} / 100 \mathrm{~g})$, and between glycine and isoleucine $(0.05 \mathrm{~g} / 100 \mathrm{~g})$. Being glutamic acid the amino acid with a higher content found in the study $(0.11 \mathrm{~g} / 100 \mathrm{~g})$.

\subsection{Sensory analysis}

\section{Acceptance test 1}

The scores of the panelists for the questions appearance, color, taste, aroma, sweetness, texture and overall impression of the product were $7.67 ; 7.92 ; 6.95 ; 6.22 ; 6.92 ; 7.15$ and $7.58 \%$, respectively. These results were quite promising for potential consumers compared to the hedonic scale of nine points, held with people engaged in physical activity. It was found that most of the panelists assigns note 8 to the questions color and sweetness (58 and $42 \%$, respectively), and Note 7 for appearance, flavor and texture (43, 22 and $35 \%$, respectively).

\section{Acceptance test 2}

According to the descriptive analysis it was found that most panelist (the Fair participants) assigned grades 8 and 9 , referring to the hedonic scale of nine points. For the question of appearance only $6 \%$ reported "like slightly" and $41 \%$ of the panelists $(\mathrm{n}=53)$ reported "like extremely"

Referring to color, 66 panelists mentioned "like extremely", expressing $52 \%$ approval, while regarding to the aroma attribute, only $23 \%(n=29)$ marked the "liked extremely" option. The flavor and overall impression, $64 \%(\mathrm{n}=35)$ reported "like extremely" and 3\% $(\mathrm{n}=4)$ "slightly disgusted". The texture and sweetness showed $35 \%$ and $28 \%$ of tasters who "liked extremely", respectively, and only $2 \%(\mathrm{n}=2)$ reported "dislike a lot".

It was observed that the 128 panelists, 55 marked the "definitely buy", 44 noted in "possibly buy", 22 marked "maybe buy / may not buy" 5 panelists "possibly not buy" and only 2 marked the "certainly not buy ", corresponding to $43 \%, 34 \%, 17 \%, 4 \%$ and $2 \%$, respectively. The results of sensory analysis showed that in general, both in the overall impression, as in appearance and sweetness, the açai gel was accepted by the panelists, with higher average scores than 6.8 (intensity of like slightly to moderately).

Table 1. Carbohydrates, fibers and minerals in the gel açai.

\begin{tabular}{cccc}
\hline Compounds & Content $(\mathbf{g} / \mathbf{1 0 0} \mathbf{g})$ & Compounds & Content $(\mathbf{g} / \mathbf{1 0 0} \mathbf{g})$ \\
\hline Fructose & $7.55( \pm 1.62)$ & Glucose & $18.94( \pm 1.36)$ \\
Fructose free & $7.54( \pm 0.08)$ & Glucose frre & $3.91( \pm 1.82)$ \\
Lactose & $0.03( \pm 1.02)$ & Galactose & $0.18( \pm 2.08)$ \\
Arabinose & $0.20( \pm 1.65)$ & Xylose & $0.36( \pm 1.04)$ \\
Mannose & $0.51( \pm 1.67)$ & Iron $(\mathbf{m g} / \mathbf{1 0 0} \mathbf{g})$ & $4.87( \pm 2.02)$ \\
Fibers & $2.11( \pm 1.94)$ & Zinc $(\mathbf{m g} / \mathbf{1 0 0} \mathbf{g})$ & $3.12( \pm 1.63)$ \\
\hline
\end{tabular}

Average $= \pm ; \mathrm{SD}=$ standard deviation; $\mathrm{n}=3$.

Table 2. Fatty acids present in the açaí gel.

\begin{tabular}{cccc}
\hline Fatty acids & Contents & Fatty acids & Contents \\
\hline Lauric and Cis-eicosenoic & $33.00 \mathrm{mg} / \mathrm{kg}( \pm 2.34 /( \pm 1.08)$ & Myristic & $55.00 \mathrm{mg} / \mathrm{kg}( \pm 1.85)$ \\
Palmitic & $1.36 \mathrm{~g} / \mathrm{kg}( \pm 2.02)$ & Margaric & $31.00 \mathrm{mg} / \mathrm{kg}( \pm 2.62)$ \\
Stearic & $0.12 \mathrm{~g} / 100 \mathrm{~g}( \pm 1.02)$ & Arachidic & $24.00 \mathrm{mg} / \mathrm{kg}( \pm 1.72)$ \\
Behenic and Lignoceric & $8.00 \mathrm{mg} / \mathrm{kg}( \pm 1.33 /( \pm 1.04)$ & Tricosanoic & $12.00 \mathrm{mg} / \mathrm{kg}( \pm 0.08)$ \\
Palmitoleic & $0.22 \mathrm{~g} / 100 \mathrm{~g}( \pm 2.92)$ & Oleic & $3.35 \mathrm{~g} / 100 \mathrm{~g}( \pm 2.32)$ \\
Linolenic & $517.00 \mathrm{mg} / \mathrm{kg}( \pm 1.45)$ & Cis- eicosapentaenoic & $7.00 \mathrm{mg} / \mathrm{kg}( \pm 1.69)$ \\
\hline
\end{tabular}

Average $= \pm ; \mathrm{SD}=$ standard deviation; $\mathrm{n}=3$. 


\subsection{Nutritional assessment and dietary habits}

The average intake of macronutrients and some micronutrients appear to be inadequate (Table 3). Carbohydrates have not reached the minimum recommended intake, while lipids and proteins were higher than adequate in most individuals.

The high consumption of these two macronutrients may cause liver and kidney overload, causing damages to the individual. Thus, it can be said that despite the average caloric intake is adequate, the distribution of macronutrients did not meet the recommendations.

It was also observed an inadequacy in the micronutrient intake. Folate and magnesium showed inadequate intake and are important as cofactors of antioxidant enzymes (Lamprecht et al., 2007). It was also found that the intake of vitamin B5, which participates in reactions that provide energy to the body, is slightly below the recommended minimum intake. Calcium, an essential nutrient for muscle contraction, bone formation and maintenance, did not achieve the minimum adequacy value. These results demonstrate nutritional risk, with the possibility of performance degradation during resisted physical activity.

In analyzing the results, individually, it was found inadequacy in at least two nutrients per volunteer. In 93\% of the sample, it was found an inadequate intake of magnesium, followed by folate and vitamin $\mathrm{D}$, both presenting lower than the recommended in $79 \%$ of volunteers. The contents of calcium and vitamin B5 revealed inadequacy of $71 \%$ and $64 \%$, respectively. In a lesser proportion all other nutrients also showed levels below the recommended, except for the iron with adequate intake in $100 \%$ of the sample.

After observing these data, it was conducted a nutritional guidance work, individually, to improve the dietary profile of volunteers, so that possible clinical needs would be avoided in order to reduce the risk of these nutritional deficiencies and harm the performance and quality of life of these individuals.

\subsection{Clinical trial and biochemical analysis}

For the selection of volunteers were considered the following exclusion criteria: not to use drugs, anabolic steroids or nutritional supplements during the survey period and not being carriers of infectious and inflammatory diseases.

Along the stages of clinical trial, 03 subjects were excluded from the sample. One of them gave up after the completion of the determination of the maximum load test (1MR) referring muscle injury during an external training. Two individuals attended only the first day of the trial of strength training session, where the exercises were performed without the gel consumption. One chose to abandon the study due to work commitments and another was excluded as a result of a viral infection in the week of testing. Thus, only 17 individuals completed the study participation.

Table 3. Macronutrients and micronutrients from the diet of individuals.

\begin{tabular}{|c|c|c|c|}
\hline & Reference & Average \pm SD & Observed Range \\
\hline Carbohyidrates (g) & $475-660$ & $411.76 \pm 109.58$ & $210.89-594.17$ \\
\hline Proteins (g) & $>102$ to 141 & $130.93 \pm 63.45$ & $50.23-275.39$ \\
\hline Lipids (g) & to 75 & $89.40 \pm 39.44$ & $31.55-154.07$ \\
\hline Fibers (g) & $20-30$ & $38.72 \pm 28.01$ & $6.31-96.97$ \\
\hline Caloric value (Kcal) & $>2350$ to 3300 & $2927.38 \pm 903.90$ & $1489.84-4521.23$ \\
\hline Vitamin A (RE) & 900 & $3060.54 \pm 3314.78$ & $72.97-10800.90$ \\
\hline Vitamin D (mcg) & 5.0 & $437.99 \pm 1601.17$ & $0.00-6000.17$ \\
\hline Vitamin B1 (mg) & 1.2 & $2.38 \pm 1.49$ & $0.49-5.55$ \\
\hline Vitamin B2 (mg) & 1.3 & $2.30 \pm 1.67$ & $0.18-6.32$ \\
\hline Vitamin B3 (mg) & 16 & $30.62 \pm 20.05$ & $3.15-64.06$ \\
\hline Vitamin B5 (mg) & 5.0 & $4.66 \pm 3.21$ & $1.18-13.81$ \\
\hline Vitamin B6 (mg) & 1.3 & $3.05 \pm 2.31$ & $0.23-7.74$ \\
\hline Vitamin B12(mcg) & 2.4 & $3.56 \pm 2.61$ & $0.00-8.38$ \\
\hline Vitamin C (mg) & 90 & $395.43 \pm 521.89$ & $1.78-1757.24$ \\
\hline Vitamin E (mg) & 15 & $20.53 \pm 15.48$ & $3.32-53.09$ \\
\hline Folate (mcg) & 400 & $247.96 \pm 155.68$ & $79.89-610.79$ \\
\hline Calcium (mg) & 1000 & $888.75 \pm 360.84$ & $437.69-1727.86$ \\
\hline Phosphorus (mg) & 700 & $1080.73 \pm 500.26$ & $105.85-1932.19$ \\
\hline Iron (mg) & 8.0 & $27.22 \pm 20.56$ & $8.26-69.66$ \\
\hline Magnesium (mg) & 420 & $259.78 \pm 147.76$ & $57.96-606.95$ \\
\hline Zinc (mg) & 11.0 & $12.59 \pm 8.96$ & $0.72-30.07$ \\
\hline Selenium (mcg) & 55 & $94.53 \pm 51.57$ & $5.97-199.57$ \\
\hline Copper (mcg) & 900 & $1.24 \pm 0.64$ & $0.34-2.44$ \\
\hline Manganese (mcg) & 2.3 & $2.57 \pm 1.88$ & $0.44-7.70$ \\
\hline
\end{tabular}

Average $= \pm ; \mathrm{SD}=$ standard deviation; $\mathrm{n}=3$. 


\subsection{Test of one Maximum Repetition (1MR)}

The maximum load for $1 \mathrm{MR}$ was detected in a maximum of four attempts in each exercise. Prior to the testing, it was done a warm up consisting of two series of fifteen repetitions with two minutes of interval between series with load established by the own individual, according to his experience in training. Between the last series of the warm up and the first attempt of the strength test, it was awarded an one-minute intervals.

\subsection{Biochemical analysis with Test $1 M R$ with and without the use of Gel}

It was observed that for both conditions there was a significant increase in total leukocyte without the use of the gel $(\mathrm{p}=0.03)$ and with use of the gel ( $\mathrm{p}=0.047)$, but the results showed that the gel was more effective in controlling the increase of this hematological parameter $(3.7 \% ; \mathrm{p}=0.047)$, as shown in Table 4.

The control conditions (no use the gel) increased significantly the concentration of total lymphocytes $(p=0.07)$ when compared to the condition using gel $(\mathrm{p}=0.153)$. This result can be considered positive, since it is considered that the control of immunosuppression in athletes in strenuous training (in this case maximum strength training), it is necessary to prevent injuries, which appearance can be associated with the risk of inflammation associated to overtraining, a condition that can cause interruption of training for muscle stress and also leads to mood and sleep disorders (Gleeson, 2007).

Biomarkers of liver and muscle stress were evaluated in the study and was found in increase in blood ammonia in both conditions $(\mathrm{p}<0.05)$.

The first day of test without the use of gel, the volunteers had blood ammonia at rest within the normal range, but after strength test at $80 \%$ of $1 \mathrm{MR}$, this elevation reached $34.7 \%$, showing that occurred energy and muscle stress after the suggested strength test. On the day of the test with use of the gel, after three days, it was observed that the athletes had slightly elevated blood ammonia (30.29 versus $47.70 \mu \mathrm{mol} . \mathrm{L}-1)$ and, after the strength test, blood ammonia was also elevated, but in a lower proportion when compared to the condition without gel (34.70 vs. $18.10 \%)$.

Nitrogen metabolites analyzed in this study, such as urea, urate and creatinine were not significantly elevated in neither conditions after strength test $(\mathrm{p}>0.05)$.

The enzymes of muscle and liver stress were assessed as total CK, LHH, GOT, GPT. There was a significant increase of CK enzyme without using of gel $(p=0.097)$ compared the experimental condition $(\mathrm{p}=0.250)$. This result was interesting and relevant because it showed that the gel was efficient in reduction of muscle stress in the group subjected to test of strength, despite being slightly higher on the test day, after use of the gel.

Similarly, this result was also observed for $\mathrm{LHH}$ with use of the gel ( $\mathrm{p}=0.285)$ when compared to condition without gel $(p=0.078)$, which showed the improvement of cellular energy conditions, especially the glycolytic or anaerobic pathway, always more active in strength activities.

Hepatic stress was observed with the analysis of the transaminases and for GOT there was a significant increase in both conditions $(\mathrm{p}<0.05)$. The GPT, in the condition without gel, was also presented high in both conditions (no gel: $\mathrm{p}=0.055$ and gel: $\mathrm{p}=0.048$ ), however, proportionally, the percentage difference in the condition with gel for this parameter was lower after strength test (27.00 versus 20.00 UL-1: $5.4 \%$ ).

Regarding biomarkers of oxidative stress was observed that for MDA, in both conditions there was a significant increase ( $p>0.05$ ), which means that, the gel did not protect the lipid peroxidation group, since the mitochondrial activity was lower for the short term resistance activity test defined in the study, however Glutathione peroxidase activity was not significantly increased in both conditions and can be observed that the GPx activity was higher in the condition without gel when compared to the experimental condition.

According to Vasconcelos et al. (2007) the lipid peroxidation process may cause changes in certain amino acids such as tryptophan, cysteine, histidine and tyrosine, responsible for formation of some proteins, generating mutagenic diseases.

Table 4. Biochemical results $(\mathrm{n}=17)$.

\begin{tabular}{|c|c|c|c|c|c|c|}
\hline \multirow{2}{*}{ Biomarkers } & \multicolumn{2}{|c|}{ Without Gel } & \multirow{2}{*}{$p$} & \multicolumn{2}{|c|}{ With Gel } & \multirow{2}{*}{$p$} \\
\hline & Pré & Pós & & Pré & Pós & \\
\hline Leucocytes $\left(/ \mathrm{mm}^{3}\right)$ & $7071.40 \pm 969.05$ & $9071.40 \pm 1911.99$ & 0.03 & $6885.70 \pm 1258.87$ & $8514.30 \pm 1491.60$ & 0.047 \\
\hline Limphocytes $\left(/ \mathrm{mm}^{3}\right)$ & $2001.90 \pm 437.99$ & $2646.30 \pm 738.22$ & 0.07 & $2095.90 \pm 416.43$ & $2463.30 \pm 481.52$ & 0.153 \\
\hline Ammonia $(\mu \mathrm{mol} / \mathrm{L})$ & $30.29 \pm 11.01$ & $76.00 \pm 15.09$ & 0.001 & $47.71 \pm 23.96$ & $85.71 \pm 29.55$ & 0.021 \\
\hline Creatine Kinase $(\mathrm{u} / \mathrm{L})$ & $179.00^{*}$ & $236.00^{*}$ & 0.097 & $305.00^{*}$ & $354.00^{*}$ & 0.250 \\
\hline Lactate Dehydrogenase $(\mathrm{u} / \mathrm{L})$ & $193.43 \pm 29.48$ & $228.57 \pm 38.29$ & 0.078 & $205.71 \pm 40.98$ & $241.43 \pm 73.92$ & 0.285 \\
\hline Trans. G. Oxalacetic $(\mathrm{u} / \mathrm{L})$ & $18.00 \pm 2.65$ & $28.57 \pm 8.62$ & 0.009 & $23.00^{*}$ & $38.00^{*}$ & 0.018 \\
\hline Trans. G. Piruvic (u/L) & $16.14 \pm 4.06$ & $27.00 \pm 12.86$ & 0.055 & $15.00^{*}$ & $20.00^{*}$ & 0.048 \\
\hline Uric acid (mg/dL) & $4.77 \pm 1.18$ & $5.31 \pm 0.94$ & 0.362 & $4.80 \pm 0.80$ & $5.10 \pm 0.80$ & 0.496 \\
\hline Urea (mg/dL) & $38.71 \pm 7.27$ & $40.71 \pm 7.39$ & 0.619 & $33.57 \pm 8.96$ & $33.86 \pm 7.15$ & 0.949 \\
\hline Creatinine $(\mathrm{mg} / \mathrm{dL})$ & $0.77 \pm 0.25$ & $0.90 \pm 0.231$ & 0.337 & $0.80 \pm 0.15$ & $0.86 \pm 0.18$ & 0.536 \\
\hline Glutathione peroxidase $(\mathrm{mg} / \mathrm{dL})$ & $9116.80 \pm 2076.45$ & $10824.00 \pm 4121.62$ & 0.347 & $8695.00^{*}$ & $9856.00^{*}$ & 0.371 \\
\hline Malonic dialdehyde $(\mathrm{mmol} / \mathrm{mL})$ & $3.36 \pm 0.47$ & $3.83 \pm 0.45$ & 0.08 & $3.39 \pm 0.53$ & $4.04 \pm 0.49$ & 0.032 \\
\hline
\end{tabular}

*Results from the Wilcoxon test. 
The control of the glutathione levels can provide important biochemical information of the oxidizing $\mathrm{x}$ antioxidant balance in the body, and at the same time allow clinical laboratory correlations with mutagenic processes, in which the quantification of glutathione as an indicator of lipid peroxidation processes levels is associated with other examinations as evidence of liver and kidney function, where there are determined important metabolites such as aspartate and alanine aminotransferase, alkaline phosphatase, urea, creatinine, sodium and potassium, being the referred the ones which map a broader biochemical profile about possible diseases associated to oxidative stress (Powers et al., 2011).

\section{Conclusions}

The chemical and nutritional composition of the gel prepared with acai pulp showed great values in the content of carbohydrates and lipids, as well as good concentrations of saturated fatty acids such as palmitic and essential fatty linolenic acid.

Sensory analysis showed that in general, regarding to both in the overall impression, as in appearance and sweetness, energy açai gel was accepted by the panelists; and that the physically active subjects analyzed in this study are potential consumers of functional açai gel. The clinical trial with the volunteers trained bodybuilders showed variation of the results for individual eating habits and anthropometric variables, due to practice of bodybuilding activities for support in fighting or to increase strength in team sports activities.

According to the biochemical findings it was observed that the gel developed provided protection for some parameters, since it modulated the immunological parameter with reduction of lymphocyte activity and muscular stress with reducing of CK activity, LHH, GPT and GPx, suggesting that gel developed showed positive results in controlling the immunological and muscular stress. However, a study with a larger number of individuals is needed to confirm the functional potential of the gel for athletes, who undergo strength activity.

It is hoped that this study can contribute to the expansion of the food chemical composition table and, consequently, with genetic improvement programs, market and social inclusion.

\section{References}

Association of Official Analytical Chemists - AOAC. (2005). Official methods of analysis of the Association of Official Analytical Chemists. 17th ed. Washington: AOAC.

Caleguer, V. F., \& Benassi, M. T. (2007). Effect of pulp, carboxymethylcellulose and arabic gum to sensory characteristics and acceptance of powdered orange drink. Food Science and Technology, 27, 270-277. http:// dx.doi.org/10.1590/S0101-20612007000200010.

Carvalho, L. M. J., Viana, D. S., Leite, D. C., Peixoto, J. C., \& Moura, M. R. (2015). Total phenolics and antioxidant activity of a functional gel based on açaí (Euterpe oleracea Martius) pulp. Journal of Advances in Agriculture, 3(3), 254-261.

Gleeson, M. (2007). Immune function in sport and exercise. Journal of Applied Physiology, 103(2), 693-699. http://dx.doi.org/10.1152/ japplphysiol.00008.2007. PMid:17303714.
Gouveia, E. C. (1978). Diagnosis of the nutritional status of the population. In N. Chaves. Basic and applied nutrition (chap. 6, pp. 254-274). Rio de Janeiro: Guanabara Koogan.

Hartman, L., \& Lago, R. C. (1973). Rapid preparation of fatty acid methyl esters from lipids. Laboratory Practice, 22(6), 475-476. PMid:4727126.

Heinrich, M., Dhanji, T., \& Casselman, I. (2011). Açai (Euterpe oleracea Martius): a phytochemical and pharmacological assessment of the species' health claims. Phytochemistry Letters, 4(1), 10-21. http:// dx.doi.org/10.1016/j.phytol.2010.11.005.

Henderson, A. (2000). The genus Euterpe in Brazil. In M. S. Reis \& A. Reis (Eds.), Euterpe edulis Martius (Palmiteiro): biology, conservation and management (pp. 1-20, Sellowia, Vol. 49). Itajaí: Herbário Barbosa Rodrigues.

Hogan, S., Chung, H., Zhang, L., Li, J., Lee, Y., Dai, Y., \& Zhou, K. (2010). Antiproliferative and antioxidant properties of anthocyanin-rich extract from açai. Food Chemistry, 118(2), 208-214. http://dx.doi. org/10.1016/j.foodchem.2009.04.099.

Lamprecht, M., Oettl, K., Schwaberger, G., Hofmann, P., \& Greilberger, J. F. (2007). Several indicators of oxidative stress, immunity, and illness improved in trained men consuming an encapsulated juice powder concentrate for 28 weeks. The Journal of Nutrition, 137(12), 2737-2741. PMid:18029492.

Laufs, U., Wassmann, S., Czech, T., Munzel, T., Eisenhauer, M., Bohm, M., \& Nickenig, G. (2005). Physical inactivity increases oxidative stress, endothelial dysfunction, and atherosclerosis. Arteriosclerosis, Thrombosis, and Vascular Biology, 25(4), 809-814. http://dx.doi. org/10.1161/01.ATV.0000158311.24443.af. PMid:15692095.

Malcher, E. S. T., \& Amaral, A. S. M. (2009). Study of the açai supply chain in the cities of Macapa, Santana, El Jadida and Laranjal do Jari. Food Hygiene, 23, 60-64.

McAnulty, L. S., Miller, L. E., Hosick, P. A., Utter, A. C., Quindry, J. C., \& Mc Anulty, S. R. (2013). Effect of resveratrol and quercetin supplementation on redox status and inflammation after exercise. Applied Physiology, Nutrition, and Metabolism, 38(7), 760-765. http:// dx.doi.org/10.1139/apnm-2012-0455. PMid:23980734.

McAnulty, L. S., Nieman, D. C., Dumke, C. L., Shooter, L. A., Henson, D. A., Utter, A. C., Milne, G., \& Mc Anulty, S. R. (2011). Effect of blueberry ingestion on natural killer cell counts, oxidative stress, and inflammation prior and after $2.5 \mathrm{~h}$ of running. Applied Physiology, Nutrition, and Metabolism, 36(6), 976-984. http://dx.doi.org/10.1139/ h11-120. PMid:22111516.

Muñoz, M. E., Galan, A. I., Palacios, E., Diez, M. A., Muguerza, B., Cobaleda, C., Calvo, J. I., Aruoma, O. I., Sanchez-Garcia, I., \& Jimenez, R. (2010). Effect of an antioxidant functional food beverage on exercise-induced oxidative stress: a long-term and large-scale clinical intervention study. Toxicology, 30(1), 8-19. PMid:19857542.

Nascimento, R. J. S., Couri, S., Antoniassi, R., \& Freitas, S. P. (2008). Composition oil fatty acids acai pulp with enzymes and extracted with hexane. Journal of Fruit Growing, 30(2), 498-502.

Peake, J. M., Suzuki, K., \& Coombes, J. S. (2007). The influence of antioxidant supplementation on markers of inflammation and the relationship to oxidative stress after exercise. The Journal of Nutritional Biochemistry, 18(6), 357-371. http://dx.doi.org/10.1016/j. jnutbio.2006.10.005. PMid:17156994.

Pietta, P. G. (2000). Flavonoids as antioxidants. Journal of Natural Products, 63(7), 1035-1042. http://dx.doi.org/10.1021/np9904509. PMid:10924197.

Powers, S. K., Nelson, W. B., \& Hudson, M. B. (2011). Exercise-induced oxidative stress in humans: cause and consequences. Free Radical 
Biology \& Medicine, 51(5), 942-950. http://dx.doi.org/10.1016/j. freeradbiomed.2010.12.009. PMid:21167935.

Rogez, H. (2000). Açai: preparation, composition and improving conservation. Belém: EDUFPA. 313 p.

Schauss, A., Wu, X., Prior, R., Ou, B., Patel, D., Huang, D., \& Kababick, J. (2006). Phytochemical and nutrient composition of the freezedried amazonian palm berry Euterpe oleracea Mart. (açaí). Journal of Agricultural and Food Chemistry, 54(22), 8598-8603. http://dx.doi. org/10.1021/jf060976g. PMid:17061839.

Spada, P. D. S., Dani, C., Bortolini, G. V., Funchal, C., Henriques, J. A. P., \& Salvador, M. (2009). Frozen fruit pulp of Euterpe oleraceae Mart. (acai) prevents hydrogen peroxide-induced damage in the cerebral cortex, cerebellum, and hippocampus of rats. Journal of Medicinal Food, 12(5), 1084-1088. http://dx.doi.org/10.1089/jmf.2008.0236. PMid:19857073.

Valko, M., Rhodes, C. J., Moncol, J., Izakovic, M., \& Mazur, M. (2006). Free radical, metals and antioxidants in oxidative stress-induced cancer. Chemico-Biological Interactions, 160(1), 1-40. http://dx.doi. org/10.1016/j.cbi.2005.12.009. PMid:16430879.

Vasconcelos, S. M. L., Goulart, M. O. F., Moura, B. F., Manfredini, V., \& Benfato, M. S. (2007). Reactive species of oxygen and nitrogen, antioxidants and oxidative damage markers in human blood: Key analytical methods for its determination. Nature Chemistry, 30(5), 1323-1338. 